\title{
Education for Rural Transformation: The Role of Community Learning Centers in Nepal
}

\author{
Tanka Nath Sharma* \\ School of Education, Kathmandu University, Lalitpur, Nepal
}

\begin{abstract}
The main purpose of this paper is to document the potential contributions of the community learning centers in the process of rural transformation and explore how formal, non-formal and informal education are blended for capital formation, empowerment and self sufficiency of the rural communities. Discussions and arguments presented in this paper are based on secondary sources supplemented by a field-based case study.

Nepal's rural communities over the years are facing poverty, deprivation and ignorance. Education and skills for life are particularly important to combat rural poverty and deprivation by developing capacity of rural people to take advantage of available opportunities for reducing economic and non-economic poverty.

Community learning centers (CLCs) as the local educational institutions outside the formal structure, can create various learning options and opportunities, responding to the diverse needs of the rural communities living in a complex situation. Referring to a case study, the paper has advocated that CLCs can be instrumental in rural transformation by offering diverse programs in education and community services such as: early childhood care and development, good quality primary education for all children, second chance basic education for youth, literacy and post literacy programs, women education program, vocational skill development, income generating programs and community development services for improving the quality of life of rural people. The paper further suggested that CLC has potential to offer assistance to the students of local schools in improving their academic achievement and to serve as a local institutional base offering technology-based open and distance learning opportunities and engage rural people in lifelong learning and continuing education.
\end{abstract}

Keywords: Community Learning Center, Education for Rural Transformation, Rural Transformation, Nepal

* Email: tnsharma@kusoed.edu.np

ISSN: 2091-0118(Print)/2091-2560(Online)

(C) 2014 JER 


\section{Introduction}

Policy makers in developing countries have placed more emphasis on rural transformation by localizing development activities. However, they hardly consider the capacity development of rural dwellers. Consequently, there can be limited rural people's participation in policy formulation, politics and, network of institutions supporting the implementation of programs (United Nations Industrial Development Organization [UNIDO], 2013). Poverty also remains a predominantly rural phenomenon. It is estimated that 70 per cent of all poor in the Asian region, or approximately 475 million, live and work in rural areas (Guimaraes, 2009) with very limited opportunities in education, health, employment and other essential services (Atchoarena, 2006). In Nepal, 83 percent of the total population resides in rural areas (Central Bureau of Statistics [CBS], 2011a).

As Poverty is a rural phenomenon in Nepal, education and skills for life are particularly important to combat poverty and deprivation, and to strengthen rural peoples' capacities to take advantage of available opportunities for reducing economic and non-economic poverty of rural people. In this connection, community learning centers (CLCs) are expected to be instrumental in creating various learning opportunities, respond to the diverse needs of the rural community living in a complex situation. To substantiate my argument, this paper has provided the national context in line with the concept of education for rural transformation, and discussed the potential contributions of the community learning centers in the process of facilitating rural transformation. Then I have presented my field based cases and discussed the findings from the theoretical lens of social transformation, participation and human capability. Discussions and arguments presented in this paper are based on secondary sources derived from published documents, research reports, professional papers and evaluation studies related to community learning centers.

\section{National Context}

Nepal has a population of 27.5 million, with 25.4 percent of the population living below the national poverty line (National Planning Commission [NPC], 2010). Nepal's human development index has improved over the years from 0.428 in 2010 to 0.458 in 2011, 0.463 in 2012 and 0.540 in 2013 (United Nations Development Programme [UNDP], 2013).

In terms of Human Development Index, Nepal is one of the ten nations making the swiftest development gains over the years (UNDP, 2010). Nepal's poverty rate is at 65 percent according to the Multidimensional Poverty Index, which assesses the nature and intensity of poverty at the individual level in health, education outcomes and standards of living. Majority of the people, especially from the rural area face discrimination in accessing education, employment, and other social services. Labor force survey (CBS, 2009) has also depicted that about $47 \%$ of the total 15 years and above population (14.4 
Million) has never been to school. Moreover, $11 \%$ of the labor force had below primary level of education.

Nepal had targeted to increase the literacy rate along with educational attainment of people in each periodic plan only after the inception of democracy in 1951 in the country. In this short period of educational history, Nepal has made significant progress in literacy achievement but it is yet far to achieve its targets. Impetus of literacy development has gained momentum with national commitment to achieve the EFA and MDG goals for the country. The recent "Literate Nepal Campaign" initiated by the Ministry of Education (MOE) is an important step to eradicate illiteracy from the country.

As a result of continued efforts and investment in education over the years through various programs and projects, there has been considerable development as well as expansion in education infrastructure especially in basic and primary education (NPC, 2011). In spite of several efforts for education development in the past, disparities have been witnessed in terms of geographical location, caste, ethnicity and gender in educational achievement. Nepal has a great diversity of race, culture, ethnicity and language. Though the diversities are the treasures of this country, they also present great challenges for the overall development including education. Moreover, caste disparities are larger than wealth and gender disparities (UNESCO, 2010).

According to National Living Standard Survey (CBS, 2011b), the literacy rate of men is $71.6 \%$ compared to $44.5 \%$ in case of women. These data show the high gender disparity in literacy. Similarly there are regional disparities in literacy. Gender disparities are worse in the rural eastern and the central plain, the mountain belt, and in the rural mid and far western hills (CBS, 2011b). Growing population of young people, low levels of education and high illiteracy, shrinking or stagnant economy, growing unemployment, caste, ethnicity and gender-based inequalities and inequitable distribution of national resources has collectively contributed to low employment opportunities and high incidences of poverty, particularly in the rural areas (Ministry of Finance [MOF], 2011; UNDP, 2009).

The above contextual review of socio-economic situation reflected the need for local educational institution facilitating employment promotion, economic growth and nonformal education connected to the rural transformation responding to diverse needs rural people for improving their quality of life (UNESCO, 2001, p. 17). Furthermore, low levels education among youths and adult population and larger number of school dropouts in the rural areas explains that conventional schooling system alone cannot meet the educational needs of all people and calls for multiple learning pathways for diverse learners and more flexibility in educating people supplemented with strong entrepreneurship skills component facilitating non-college bound youths to start small enterprises and engage in selfemployment (ADB, 2011). The situation calls for local institution, multitude of education and community service programs for improving quality of life of rural people leading to rural transformation. 


\section{Conceptual Understanding of Education for Rural Transformation}

The rural transformation agenda is about improving overall quality of life of people in the rural areas (Boto \& Fotabong, 2012; Olawepo \& Ariyo, 2011). The core ideas are concerned with improving the well-being of rural people through enhancing their productive capacities, expanding their choices in life and implementing pro-poor nondiscriminatory public policies (UNESCO INRULED, 2012. p. 3). Education has been seen as a means of developing capabilities, promoting employment potentials, and ultimately reducing poverty of people in the rural communities (UNESCO, 2001; Atchoarena, 2006). As rural communities have complex situations and diverse learning needs, the nationally designed formal schooling system alone has been unable to fully serve the educational needs of the rural communities. This demands program diversity, flexibility and provisions for multiple learning options available to communities in building skills and capacities for harnessing opportunities and improving livelihood and enhancing quality of life of rural people (Coker \& Bassey, 2012).

As education is regarded as a prerequisite for rural transformation, the relationship between education and rural transformation is very clear: educated people have higher income earning potential, and are better able to improve the quality of their lives (International Labour Organization [ILO], 2012). Persons with at least a basic education are more likely to avail of a range of social services, and to participate more actively in local and national government through civic involvement. They are less likely to be marginalized within the larger society. Education empowers; it helps people become more proactive, gain control over their lives and widen the range of available choices (Asian Development Bank [ADB], 2002). Similarly, the issue of marginalization can be addressed through empowering people with education which would make them politically, socially and economically aware. This awareness can be directed towards the involvement of people in community participation for their own development (Acker \& Gasperini, 2009). In simple terms education is able to give voice to individuals and a clear understanding of rational and irrational behavior. The power in the people to understand what's right and wrong for them helps to attain positive individual growth which ultimately leads to overall growth of the nation.

The majority of the people in rural Nepal are deprived of education and other essential services. Diverse educational and skill development needs of rural people who are not served by the formal education system can be addressed by the community learning centers that can connect education and training with rural transformation through informal and nonformal education programs (Wim, 2006).

Here I would like to present a successful community building approach which is known as Community Learning Centre. It is a local institution outside the formal education system designed to serve rural or urban areas, usually set up and managed locally to provide 
learning opportunities for community development and to improve local people's quality of life (HDNCG, 2012). CLCs are viewed as having numerous potentialities to contribute to the rural transformation that proves opportunities for learning for all in various spheres of life. Continuous involvement of grassroots level people in the overall development and operation of CLC is essential for it to become a self-sustaining asset of the community. The primary aim of any CLC is to empower individuals, to promote community development programs, and to provide life-long education for all for improving the overall quality of life of communities (Jennings, 2005; HDNCG, 2012). In other words, the major emphasis of CLC is to enable people to fight against income poverty and capability poverty. In this context, CLC opens up new avenues for deprived, disadvantaged and marginalized people to learn to be creative, analytical and productive, and also to be able to make their own choices in making decisions (UNESCO, 2008) and transform their society.

The CLC can be the institutional vehicle for offering flexible and open learning opportunities to rural people to learn in their own pace and time. The merits and potentials of such non-formal and life-long learning should be deeply explored (Zhang, 2011, p. 56). It is important that educational institutions and communities are to be brought together (Gardiner, 2008; HDNCG, 2012) in order to develop key link between education and rural transformation. Community learning centers which are owned by the community member can make it possible to develop such link.

\section{Theoretical Framework}

One of the greatest challenges facing Nepal's communities over the years is poverty, deprivation and ignorance that have produced the social exclusion. Combating these challenges is not enough through simple reform but it requires the complete leap of "rural transformation" (Mezirow, 1989; Castles, 2001; Richardson \& London, 2007; Boto \& Fotabong, 2012). Transformation evidenced by achieving three outcomes: (1) creating community wealth, (2) increasing civic participation and/or inclusive leadership (3) greater family self-sufficiency. Community wealth creation and increased civic participation, and inclusive leadership collectively cultivate greater family self-sufficiency (Richardson \& London, 2007) (See Annex I for theoretical framework).

Out of the three dimensions of rural transformation presented above, the wealth is generated through income generating activities organized by CLCs, start enterprises utilizing available resources. In addition, CLCs as learning centers contribute in creating learning environment and avenues for delivering effective formal, non-formal and informal modes of learning responding to the diverse learning needs of rural communities (Zhang, 2011; Coker \& Bassey, 2012). The second dimension of rural transformation is, as explained by Richardson \& London (2007), increasing "civic participation" (Chambers, 1997, 2009) and/or promote social inclusion which are the core activities of CLC. The participation has promoted the effective, energized and innovative leadership. 
Consequently, it has fostered optimism among the community people which is most likely to stimulate rural transformation (UNESCO, 2001).

Participation and active involvement of rural people in learning and development process creates the environment for them to become conscious about their rights and responsibilities, capable of solving their life problems and gain insight and vision to lead and serve as change agents for transforming their community and ultimately improving their quality of life (ILO, 2012). Such environment opens up the opportunities for several minority groups to participate in healthy competition not only to gain power but also optimized their hope to be successful leader. It has also potential for networking and collaboration among the government agencies, nongovernmental organizations and communities based organizations and pull their support for diversifying programs and meeting resource needs by utilizing strengths and resources of the local communities.

The third concern of rural transformation, as explained by Richardson \& London (2007), is self-sufficiency which can be promoted through CLC in several ways such as expanded knowledge base, acquisition and application of new and relevant skills and formation of enabling attitudes. This has not only promoted the individual ability but has also promoted the life skills of community people (Gardiner, 2008). CLCs can offer various modes of learning and pathways through formal, non-formal and informal approaches to provide access and opportunity to every citizen (who wish to) continue their education, learn and upgrade skills and engage in lifelong learning process, contributing to develop self-sufficiency among the rural people. This has improved the quality of life of people in the community by providing an opportunity to transform capability of the individuals in their social and economic life (Sen, 1999, 2002, 2005). This above explanation shows that CLC contributes to a community by creating wealth, increase civic participation and cultivate a greater family self-sufficiency. This may be the reason that it is highly prioritized in the context of community development. Particularly in the context of Nepal, this set up has been initiated in almost all VDCs and districts. As of 2010, there were only 931 CLCs in operation in the country further 900 CLCs were underway (UNESCO \& H. D. Nepal, 2011). Out of all these community development initiatives in the form of CLC, I have presented the case of Shikharapur CLC in this article.

\section{Case Study: Shikharapur CLC}

\section{Introduction}

As explained above, CLCs are formed in most of the districts of Nepal. Each district has several CLCs. For example, altogether 29 CLCs are currently registered in Kathmandu district alone (N. Shrestha, personal communication, 19 June 2014). Some CLCs cover more than one Village Development Committee. Shikharapur CLC, established in 2006 and located about 10 KM away from Kathmandu in Shesh Narayan Village Development 
Committee has its coverage of 6 VDCs with an area of about 46,000 square kilometer and population of 24,000 .

With the motto "If not done here then where? If not now then when? If not me then who?" Shikarapur CLC has emerged as an energized platform for the development of the local community. CLC Shikharapur is guided by the concept of "Model Education Village" with a mission of "A School for community". A School for Community is a concept of an open school for all those living in the community and believes itself to be a school where experiences are shared by individuals of the community. They can exchange ideas and information with others as a part of education. The success story of Shikarapur CLC is based on the strong culture of applying collective efforts and bearing shared responsibility by all the stakeholders.

\section{Programs of CLC Shikarapur}

CLC Shikharapur has been conducting various activities with the support of the government and with its own resources in education, community development, income and productivity increase and community services. Details of the programs being offered by Shikharapur CLC is briefly described in the following section.

\section{Programs in Education}

CLC Shikharapur envisioned to make Shikharapur a 'Model Educational Village'. To achieve this goal, multiple educational programs are being offered to respond to the need of diverse learners and provide them with multiple learning options utilizing formal, nonformal education, and informal modes of learning.

Formal education program. Shikharapur CLC has promoted formal education programs by making them accessible to learners in the community through development and management of Sikharapur Community Campus, Community School and early childhood development center. These formal education programs are unique in nature being operated within the CLC framework. The CLC also has extended its support services to schools in their target area to enhance the quality of education in local schools. Since ECD, Primary and Secondary School and College are being operated within the CLC premise, children and youth of Sikharapur community have convenient access to all levels of formal education in their own community.

Non formal education program. Under non-formal education program of Shikharapur CLC is offering literacy classes in six Village Development Committees (VDCs) with the target of accomplishing 100\% literacy rate in all of these VDCs. Shikarapur CLC is the first CLC which lunched the literacy campaign to support the "National Literacy Campagin" of the government of Nepal. Literacy program of CLC has provided new life to illiterate people in the community and has paved the way for lifelong learning. One participant of 
literacy program said: "I can read and write now, I am feeling like coming out from dark room to day light".

Flexible School Program (FSP). It is another important program which is in operation as a part of non-formal education to create learning opportunities for youth and adults who dropped from the school in their early years and has aspiration to continue their education. Young children and youth in the community have benefitted from FSP by attending primary and lower secondary FSP programs with options either to enter into the formal school programs or continue their education through Open School Program (OSP).Open School Program offered by CLC serves dropout students of the community to continue their education. Many out of school youth, as a result, have successfully completed their School Leaving Certificate which has opened up avenues for their self-development, consequently leading to community development.

It has initiated a similar program, women school, targeting females who quit schooling in their early years and had no opportunity to learn. Women School has helped the illiterate and post-literate women to complete their schooling under CLC framework. Open learning and adult learning have thus been implemented effectively benefiting all participants. . The women school program is partly supported by women teachers who are employed within the CLC's service area with the teachers paying 50 Rs per month from their monthly salary. One of the participants of open school program and currently studying in the community's college said "I had never expected that I would be studying at the college level; CLC has changed my life".

Informal education program. A farmer's school has been created by developing a model farm through which farmers receive information to improve farming techniques and practices and agricultural productivity. CLC has leased land and developed demonstration farm to train the farmers to apply improved farming techniques and use modern technology for incrasing productivity and income. Farmers from service VDCs become members of this school. In the school, the farmers test and grow vegetable and crops that has high value and market. The products made in the farm are sent to the market and the income is considered as the CLC income.

Shikharapur CLC disseminates printed materials to the community people. Sikharapur CLC also owns a computer lab connected by wireless internet offering service to the people from the community. The local women are now able to make video call through skype to their family members and relatives living abroad. A library was established in order to fulfill the pre-requisites of Shikharapur community campus established in 2005. Though the library service was intended for the college students, it was made accessible to all the members of the community. There are altogether three thousand books and other resources available in the library including newspapers. 


\section{Community Development and Income Generation}

Shikarapur CLC empowers people becauseit helps mobilize community people and available local resources to help themselves. It encourages local people to formulate their own plans and programs as suited to their milieu. It has been organizing various advocacy campaigns on women's rights, education rights and child rights. Income and productivity improvement, community services and networking and collaboration are three main components of community development and income generation activities.

Income and productivity improvement. Vocational skill development, occupational skill enrichment programs and entrepreneurship development have been carried out for promoting income generation under CLC. Community members are provided with training to generate income using locally available resources. Lapsi and pears are fruits that grow naturally in that locality. Community members are trained to increase their productivity, process fruits and market products.Similarly, Shikharapur CLC organizes skill training in areas demanded by the community people and develop skills of out of school youthin order to make them employable or engage in self employment. These skill training programs are organized with the support from respective government agencies or from the nongovernmental organizations.

Community services. CLC has conducted community services of environmental concern and social awareness. Various awareness raising programs are carried out through different social events. CLC has made a bottle house, which is made out of waste and throw-away bottles to spread the message of proper garbage management in the community. The CLC members celebrate various occasions such as Children's Day, Environment Day, Women's Day, AIDS' day and paddy festival. Farmer's gathering is organized by inviting experts on production technique to equipfarmers with new knowledge. The gathering is held in bottle house. Monthly health campaigns especially for women are arranged. Shikrapur CLC promotes community health by arranging tohave a doctor visit once a week to offer health services.

Community services through networking collaboration. To overcome the prevailing problem of financing and sustainability, Sikharapur CLC has envisioned the concept of developing Pharping area as a model education village where people in the community have easy access to essential services and various resources. For this purpose, Shikharapur CLC has attempted to form educational partnership with all community schools. It has developed networking collaboration with the potential support providers to mobilize resources for community service programs. The team approaches sectoral ministries to bring their services to the community. Health services, agricultural extension services, food processing techniques and enterprise development are some examples of these services. 


\section{Governance and Management}

The successful implementation of any program depends on governance pattern and management style. Credibility and trustworthiness of CLC management is maintained through transparency and commitment to accountability to the community people. The detailed activities of Shikarapur CLC are published in its website, and details of income and expenditure of the CLC are displayed in the notice board for the public.

Since the CLC is developed through total involvement of the community, very high dedication and commitment of the management committee, officials, teachers and facilitators have been critical. . The founder of Shikrapur CLC said, "Shikrapur CLC has become a model CLC nationwide and if such CLC can be extended nationwide, it can bring a revolutionary development in the country". The management committee of Sikharapur is inclusive and decisions are made in a participatory manner. Out of seven members of the committee four are women. The management committee is committed for the development of CLC to transform their villages as "Model Education Villages".

\section{Constraints and Challenges}

Although Sikharapur CLC is successful in bringing various educational and community service programs through its collaborative network, the available supports are contributed from personal contacts and connections. Regular financial support from the government and various donor agencies through a systematic process is yet to be established (HDNCG, 2011). Although, the existing team of individuals in this CLC is highly committed to the development of CLC, the absence of a solid legal foundation of CLCs has restrained bringing programs and budgets from various sectoral ministries and organizations. Human resources required for successfully operating flexible and diverse educational programs are not readily available. Non-formal education is carried out by the individuals who were educated through formal schooling. Changing the formal mindset into non-formal/informal approach to learning is also a challenge. Shikharapur CLC has built basic infrastructure (though not sufficient) to operate open and distance education as a part of lifelong learning and continuing education opportunity to the community. But it requires technical expertise and systematic government technical and financial support to make it sustainable.

\section{Discussion of Findings}

Education has transformative potential if it is connected to people's life and their livelihood (Sen 2005). The case presented above has attempted to connect education, training and community development services to people's life and make them supportive to people's livelihood. The information generated from the case showed that in a situation where there are highly committed influential leaders and management committee members who has ability to influence and inspire the community members supported by sufficient 
resources, CLC can offer diverse educational and community services responding to the complexity of the rural society.

As described above, the CLC has offered a spectrum of educational services ranging from early childhood care and development, primary education for all children, and second chance basic education for adolescents and youth, to literacy and post literacy programs, women education program, vocational skill development, and income generating programs and community information services.

As stated in the case study, Community Learning Center has attempted to capture the essential requirements of adult learning described by Milana (2012). For example, it has attempted to: (a) equip people with necessary skills to function in society (b) promote democratic participation of the stakeholder, (c) promote the access to adult learning activities, (d) enhance literacy skills, (d) caring for personal health, (e) enhance farmers' understanding in improved agricultural practices for improving agricultural productivity. The educational initiatives occurring in CLC Sikharapur are also responsive to the cultural and political globalization that makes human rights a universal concern (Sen, 2005).

CLC under study has attempted to initiate life-long learning which focuses on two aspects: (a) active citizenship and (b) employability (Milana, 2012). Active citizenship relates to applying existing knowledge and acquiring information and skills for, active planning of one's own life and continuing participation in learning activities. Active citizenship and employability are interconnected and contribute to wealth creation and social capital formation. All of these three dimensions of lifelong learning have been captured by CLC under study. However, in absence of a system of recognizing informal and non-formal learning, lifelong learning has not evolved yet as a well-recognized component of the system of education in Nepal.

Participation and civic engagement which is one of the dimensions of rural transformation are applied by CLC. CLC under study engages rural people in identifying their needs, planning programs, managing their resources, and participating in monitoring results. Participation and involvement are accepted as important requirements of CLC which builds on a livelihood approach to rural transformation.

To sum up, it can be said that Sikharapur community learning center has attempted to organize education in all forms and at different levels, for the purpose of equipping people with skills and knowledge and enhancing their capacities, networking with the development partners in bringing the development services at the doorstep of the rural community for their welfare and benefits as stated by Zhang (2011). These are obviously the key elements of rural transformation. Greater, attention, however, is needed on the part of the government to professional and advanced education to serve the needs of rural people and transform the rural community. 
ICT based distance education is another potential area of CLC to develop and expand learning opportunities for rural people and engage them in lifelong learning and continuing education. CLCs can be appropriate venue for technology-based open and distance learning. This powerful means of educating rural communities from basic education to higher levels of education has not received adequate attention.

\section{Conclusion}

Community Learning Centers can be successful in offering various education programs for rural transformation provided that they are supported with needed resources, strong legal foundation and policy support along with active civic engagement and highly committed management teams. These requirements, to the extent that these are fulfilled, would allow CLCs to contribute to rural transformation. Thus CLCs can enable individuals and communities to survive, to develop their full capacities, to live and work in dignity, to participate fully in development, to make informed decisions and to continue learning.

Community participation, their involvement in all phases of program selection, planning, resourcing implementation and monitoring have been demonstrated to be essential practices for the promotion of effective CLC activities. Inclusiveness and empowerment of CLC participants are also critical ingredients of a successful CLC. But empowerment is less likely to happen from external interventions; rather it is something that evolves from within through education and civic engagement in the transformative process.

\section{References}

Acker, D., \& Gasperini, L. (2009). Education for rural people: The role of education and training and capacity development in poverty reduction and food security. Rome, Italy: FAO.

Asian Development Bank. (2002). Education - Our framework policies and strategies. Manila, The Philippines: Author.

Asian Development Bank. (2011). Economic trends and prospects in developing Asia:

South Asia. Manila, The Philippines: Author.

Atchoarena, D. (2006). The evaluation of international cooperation in education: A rural

perspective. Journal of International Cooperation in Education, 9(1), 59-70.

Boto, I., \& Fotabong, E. (2012). Major drivers for rural transformation in Africa:

Resources on rural transformation in Africa (Issue Brief No. 24). Retrieved from http:// brusselsbriefings.files.wordpress.com/2012/10/br-24-rural-transformation-in-africa-eng. pdf

Castles, S. (2001). Studying social transformation. International Political Science Review, 22(13), 13-32. doi:10.1177/0192512101221002

Central Bureau of Statistics. (2009). Report on Nepal labour force survey 2008. Kathmandu, Nepal: Author. 
Central Bureau of Statistics. (2011a). Preliminary results of national population census 2011. Kathmandu, Nepal: Author.

Central Bureau of Statistics. (2011b). Nepal living standards survey 2010/11. Kathmandu, Nepal: Author.

Chambers, R (1997). Whose reality counts? Putting the first last. London, England: Intermediate Technology Publications.

Chambers, R. (2009). So that the poor count more: using participatory methods for impact evaluation. The Journal of Development Effectiveness, 1(3), 243-246.

Coker, M. A., \& Bassey, U. (2012). Problems and prospects of implementing rural transformation programmes. Young Researchers, 2(2), 26-34.

Gardiner, M. (2008). Education in rural areas (Issues in Education Policy No.4). Johannesburg, South Africa: Centre for Education Policy Development Johannesburg.

Hammer, P. C., \& White, L. J. (2012). 21st century community learning centers: A descriptive evaluation for 2011-2012. Charleston, WV: West Virginia Department of Education, Division of Teaching and Learning, Office of Research.

HDNCG. (2011, April). Report on assessing the condition of community learning centres (CLCs) in Nepal to Achieving Education for All goals. Kathmandu, Nepal: UNESCO.

International Labour Organization. (2012). Rural development through decent work: Rural policy brief. Retrieved from http://www.ilo.org/wcmsp5/groups/public/@ed_emp/ documents/publication/wcms_158583.pdf

Jennings, W. (2005). Community learning centers. Design share. (Reprinted from Bold Plans for School by L. Elbaum, 1998, Industrial Aveue: Mahwah)

Jumani, N. B., Rahman, F., \& Bibim, K. (2011). Potential of non formal basic education in promoting women education in pakistan. International Journal of Instruction, 4(1).

Mezirow, J. (1989). Transformation theory and social action: A response to collard and law. Adult Education Quarterly, 39(169), 169-175. doi:10.1177/0001848189039003005

Milana, M. (2012). Globalization, transnational policies and adult education. International Review of Education, 58(6), 777-796.

Ministry of Finance. (2011). Economic survey, fiscal year 2010/11. Kathmandu, Nepal: Author.

National Planning Commission. (2010). Millennium development goals needs assessment for Nepal. Kathmandu, Nepal: Author.

National Planning Commission. (2011). Three year interim development plan 2011-2014. Kathmandu, Nepal: Author.

Olawepo, R. A., \& Ariyo, B. (2011). Facilitating rural transformation through community banking: An example from Kogi State, Nigeria. International Journal of Business and Social Science, 2(5). 
Richardson, J. A., \& London, J. K. (2007). Strategies and lessons for reducing persistent rural poverty: A social-justice approach to funding rural community transformation. Journal of the Community Development Society, 38(1), 92-107.

Sen, A. (2005). Human rights and capabilities. Journal of Human Development, 6(2), 151166.

Sen, A. (1999). Development as freedom. New York, NY: Oxford University Press.

Sen, A. (2002) Rationality and freedom. Cambridge, MA: Harvard University.

United Nations Development Programme. (2013). Human development report 2014. New Kathmandu, Nepal: Author.

UNDP. (2009) Nepal human development report 2009: State transformation and human development. Kathmandu, Nepal: Author.

UNESCO. (2001). Education for rural transformation: Towards a policy framework. China: International Training and Research Center for Rural Education.

UNESCO. (2008). International literacy statistics: A review of concepts, methodology and current data. Montreal, Canada: Author.

UNESCO. (2010). EFA global monitoring report 2010: Reaching the marginalized. Paris and London: UNESCO Publishing and Oxford University Press.

UNESCO \& H.D. Nepal. (2011). Assessing the condition of community learning centres (CLCs) in Nepal to achieving education for all goals. Kathmandu, Nepal: Author.

UNESCO/INRULED. (2012). Education and training for rural transformation: Skills, jobs, food and green future to combat poverty. China: Author.

United Nations Industrial Development Organization. (2013). Rural transformation: Promoting livelihood security by adding value to local resources. Vienna, Austria: Author.

Wim, H. (2006). Non-formal education and basic education reform. Paris, France: Institute of Educational planning.

Zhang, W. (2011). Reaching the marginalized rural poor: A study of multi-purpose community learning center in Yunnan, China. Bangladesh Education Journal, 10(1), 47-58. 
Annex I

Theoretical framework

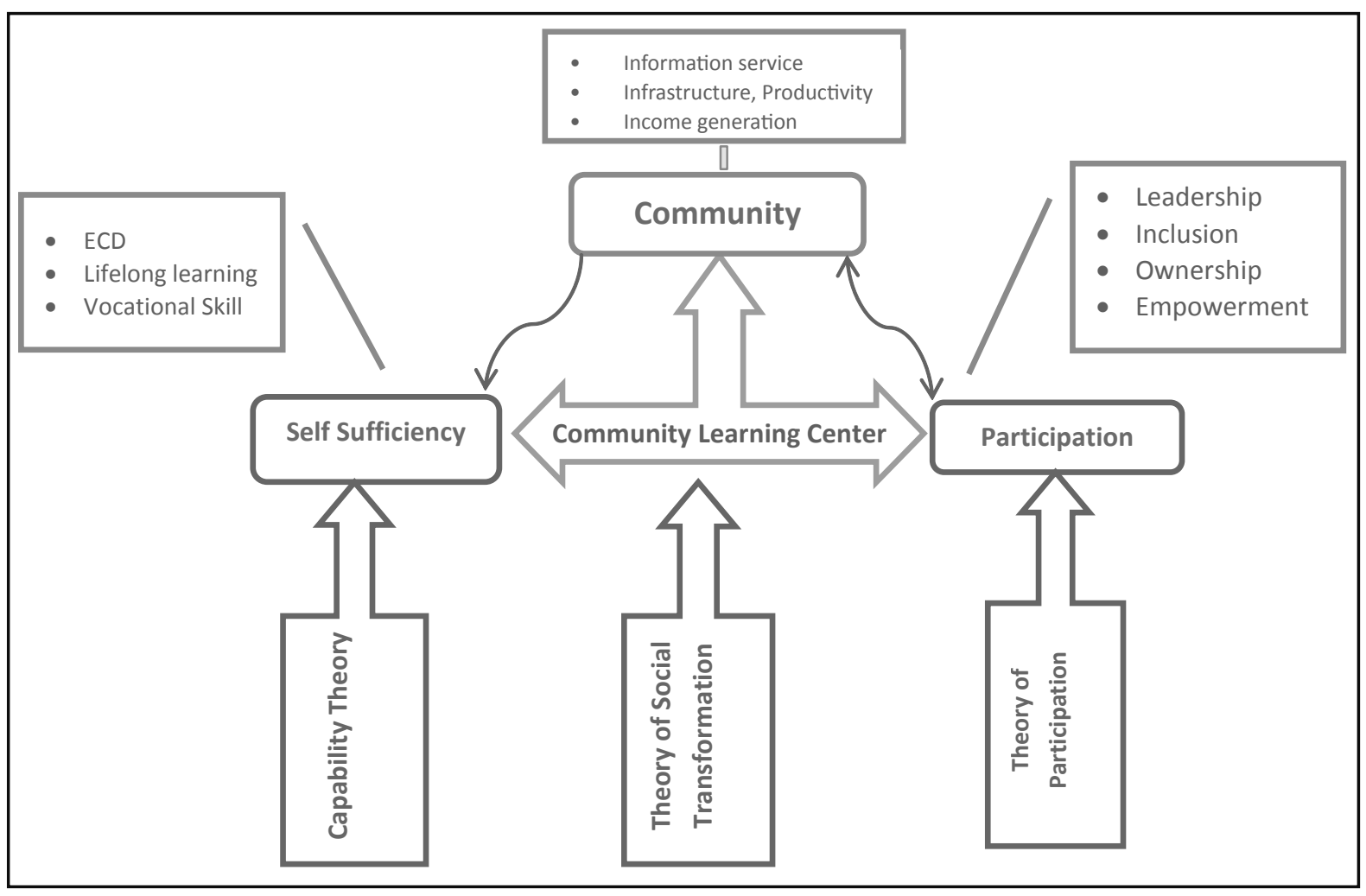

Journal of Education and Research, August 2014, Vol. 4, No. 2 